\title{
Surgical Treatment of Obstructed Left-Sided Colorectal Cancer Patients
}

\author{
Young Jin Kim \\ Clinic of Colorectal Cancer, Department of Surgery, Chonnam National University Medical School, Gwangju, Korea
}

\section{See Article on Page 251-258}

Colorectal cancer is the single most common cause of large intestinal obstruction. Approximately 2\% to 5\% of colorectal cancer patients have an obstruction. Cancer arising in the rectum or left colon is more likely to obstruct than cancer arising in the proximal colon. Acute colonic obstruction produces a dilated bowel with a large amount of fecal loading that is proximal to the blockage and is associated with bacterial overgrowth and impairment of blood flow.

The preferred treatment of mid or lower rectal cancer obstruction is a loop colostomy, followed by neoadjuvant chemoradiation and a resection of the primary tumor at a later time. The surgical options for the treatment of left-sided colon-cancer obstruction are a Hartmann's operation, a sigmoidectomy with primary colorectal anastomosis with or without intraoperative colonic lavage, and an abdominal colectomy with ileorectal anastomosis [1].

A bridge to surgery using a stent showed reductions in both postoperative morbidity and mortality when successful [2]. The technical and clinical success rate was over $90 \%$ for stenting. Although complications of the procedure include stent migration, blockage, and perforation, stenting helps reduce the postanastomotic leak rate, the wound infection rate, and the length of the hospital stay and has survival rates comparable to those of an emergency resection [3]. However, other reports indicate that the insertion of a self-expandable metallic stents as a bridge to surgery in the management of left-sided colon-cancer obstruction is pos-

Correspondence to: Young Jin Kim, M.D.

Department of Surgery, Chonnam National University Hwasun Hospital, Chonnam National University Medical School, 322 Seoyang-ro, Hwasun 519-763, Korea

Tel: +82-61-379-7642, Fax: +82-61-379-7661

E-mail: kimyjin@jnu.ac.kr

(c) 2014 The Korean Society of Coloproctology

This is an open-access article distributed under the terms of the Creative Commons Attribution NonCommercial License (http://creativecommons.org/licenses/by-nc/3.0) which permits unrestricted noncommercial use, distribution, and reproduction in any medium, provided the original work is properly cited. sibly associated with adverse oncologic outcomes compared with nonobstructed elective surgery [4].

Increasing amounts of data suggest that a primary anastomosis without a bowel preparation or with an on-table lavage, with or without a diverting ileostomy, may be equally safe. The postoperative morbidity for a single-stage operation with intraoperative lavage with a new intraoperative colonic irrigator (Dalim Co., Seoul, Korea) for obstructive left colorectal cancer was comparable to that for nonobstruction left colorectal cancer [5]. However, the postoperative mortality in the obstruction group was significantly higher than it was in the nonobstruction group [6]. A number of studies have demonstrated the safety and the efficacy of on-table colonic lavage for avoiding a colostomy without increasing the leakage rate $(<5 \%)$ or the sepsis rate [7]. I usually do the primary anastomosis after irrigation of the proximal colon with a 24-Fr Foley catheter through the appendectomy stump in patients with a left-sided colon-cancer obstruction. However, I think if the bowel looks compromised or if the patient is unstable, malnourished, or immunosuppressed, a resection with diversion remains safe. If a suitable strategy for managing obstructed left-sided colorectal-cancer patients is to be established, further randomized controlled studies on the surgical morbidity and the oncologic outcome between the bridge to surgery using a stent and a singlestage operation with intraoperative lavage are needed.

\section{REFERENCES}

1. Townsend CM Jr, Beauchamp RD, Evers BM, Mattox KL. Sabiston textbook of surgery: the biological basis of modern surgical practice. 19th ed. Philadelphia: Elsevier Saunders; 2012.

2. Grundmann RT. Primary colon resection or Hartmann's procedure in malignant left-sided large bowel obstruction? The use of stents as a bridge to surgery. World J Gastrointest Surg 2013;5:1-4.

3. Saida Y, Sumiyama Y, Nagao J, Uramatsu M. Long-term prognosis of preoperative "bridge to surgery" expandable metallic stent insertion for obstructive colorectal cancer: comparison with emergency operation. Dis Colon Rectum 2003;46(10 Suppl):S44-9.

4. Kim JS, Hur H, Min BS, Sohn SK, Cho CH, Kim NK. Oncologic 
outcomes of self-expanding metallic stent insertion as a bridge to surgery in the management of left-sided colon cancer obstruction: comparison with nonobstructing elective surgery. World J Surg 2009; 33:1281-6.

5. Kim JH, Shon DH, Kang SH, Jang BI, Chung MK, Kim JH, et al. Complete single-stage management of left colon cancer obstruction with a new device. Surg Endosc 2005;19:1381-7.

6. Jung SH, Kim JH. Comparative study of postoperative complica- tions in patients with and without an obstruction who had leftsided colorectal cancer and underwent a single-stage operation after mechanical bowel preparation. Ann Coloproctol 2014;30: 251-8.

7. Torralba JA, Robles R, Parrilla P, Lujan JA, Liron R, Pinero A, et al. Subtotal colectomy vs. intraoperative colonic irrigation in the management of obstructed left colon carcinoma. Dis Colon Rectum 1998;41:18-22. 